\title{
Ghrelin attenuates drowning injury via dual effects on damage protection and immune repression
}

\author{
Min Chen, Hongwei Lin, Yanjun Gao, Zaiqiang Wang, Yujuan Li, Faguang Jin \\ Respiration Department of Tangdu hospital, Air Force Military Medical University, Xi'an, China \\ Contributions: (I) Conception and design: F Jin; (II) Administrative support: F Jin; (III) Provision of study materials or patients: M Chen, H Lin, Y \\ Gao; (IV) Collection and assembly of data: M Chen; (V) Data analysis and interpretation: Z Wang, Y Li; (VI) Manuscript writing: All authors; (VII) \\ Final approval of manuscript: All authors. \\ Correspondence to: Faguang Jin. Respiration department of Tangdu hospital, Air force military medical university, Xinsi Road \#1, Xi'an 710038, China. \\ Email: jinfag@fmmu.edu.cn.
}

Background: Seawater drowning is the major cause of accidental injury and death. The current treatment
could not essentially block the source of the damage due to the complex etiology. Therefore, it is urgent to
clarify the detailed mechanisms and find effective therapeutic approaches. Methods: We performed in vitro experiments to evaluate the damage of seawater drowning to lung epithelial cells. FACS, immunofluorescent staining, and western blot were used to detect the apoptosis. CCK-8 assay, Ki67 staining, and cell cycle analysis were used to assess the proliferation. The cytokine expression was determined by qRT-PCR and ELISA. Western blot and reporter assay were used for regulation mechanism study. For neutrophils development, Transwell assay and FACS were used for further investigation. Besides, in vivo study was performed with the seawater drowning model in rats.

Results: In this study, we found that seawater drowning induced mitochondria damage, which further accelerated epithelial cell apoptosis and repressed cell proliferation. Administration of ghrelin attenuated the mitochondria damage via reducing ROS generation, decreasing the concentration of calcium ion and ceremide, and promoting ATP production. Besides, exogenous ghrelin also rescued the cell survival inhibited by seawater simulants. Mechanically, ghrelin retrieved the influence of seawater via inhibiting NF- $\kappa \mathrm{B}$ signaling activation, and agonist of NF- $\mathrm{NB}$ could offset the function of ghrelin. Besides, ghrelin reduced the expression of inflammatory factors and chemokines responsible for neutrophils activation and recruitment, by which ghrelin suppressed the immune response. The further in vivo experiments also indicated that ghrelin treatment restored the apoptosis promotion and inflammation activation function of seawater simulants, and further alleviated the lung tissue injury.

Conclusions: Our study revealed the dual effect of ghrelin on seawater drowning induced lung injury via damage protection and immune repression, providing new insights into drowning injury pathogenesis and therapeutic strategies.

Keywords: Seawater drowning; ghrelin; NF-кB; ROS; neutrophil

Submitted Feb 19, 2021. Accepted for publication May 13, 2021.

doi: $10.21037 / \mathrm{atm}-21-795$

View this article at: http://dx.doi.org/10.21037/atm-21-795

\section{Introduction}

Drowning is the third leading cause of accidental injury and death $(1,2)$. The latest epidemiological survey result indicates that more than 370 thousand people die from drowning worldwide annually (3). Lung injury is the most common complication among all the drowning patients, in which nearly one-third of these patients would develop ultimately into acute lung injury (ALI) or acute respiratory distress syndrome (ARDS) $(1,4)$. In recent years, it becomes more and more popular to exploit marine resources or 
take seaside vacations, and the frequency of accompanied seawater drowning accidents is also increasing. Therefore, it is necessary to elucidate the mechanism of ALI induced by seawater drowning.

When the victims are suddenly immersed in seawater, the direct harmful consequences of drowning are respiratory impairment and hypoxia. The accumulated carbohydrate and consumed oxygen can trigger ALI/ARDS and cause a variety of systemic complications, such as cerebral hypoxia and cardiovascular diseases (5-7). Then, the hyperosmotic seawater produces strong injury stimulus in the lungs and alveoli, including DNA damage, autophagy, and apoptosis (8-10). The fluid from capillaries enters the alveolar cavity due to the osmotic pressure and results in pulmonary edema $(11,12)$, which aggravates the progress of ALI/ARDS. Additionally, overproduction of ROS and activation of oxidative stress play significant roles in ALI/ ARDS. Although no direct evidence indicates that seawater can promote ROS generation or induce oxidative stress, it has been demonstrated that seawater exposure indeed induces the expression of myeloperoxidase and impairs the total superoxide dismutase activity (13). Besides the direct damage to lung tissue, seawater also stimulates the local immune response of injured tissues. It has been reported that seawater instilling through the trachea may increase the permeability of alveolar-capillary, resulting in the exudation and recruitment of immune cells, such as neutrophils and macrophages $(14,15)$. The activated neutrophils and macrophages further generate excessive inflammatory cytokines and evoke the Th1 response $(13,14,16-18)$. The previous studies have demonstrated that multiple signaling pathways are involved in seawater-mediated immune response activation, including NF $\kappa B(13)$, STAT1 (16), Hif$1 \alpha$ (12), p38 (19), and so on (20). It is critical to elaborate the detailed and comprehensive molecular mechanisms of seawater-drowning injury.

Although the pathophysiological of seawater-drowning induced ALI/ARDS are well-known, no effective treatment or therapeutic strategy is available at present. The researches based on animal models indicate indicated several potential treatments on seawater-drowning injury (21-23). Some strategies predominantly target immune repression after seawater inhalation, such as dexamethasone and dihydroxy vitamin D3. And Estradiol and tanshinone IIA can relieve pulmonary edema. However, the biosafety assessment and detailed mechanisms of the above medicine need further investigated. Ghrelin, which is a 28 -amino acid peptide produced by the stomach, acts as an endogenous ligand of growth hormone secretagogue receptor (GHSR) and alleviates inflammatory response in multiple diseases (24-26). It has been reported that the production of ghrelin decreased gradually during ALI progression, and presents protective function on ALI with different animal models, such as sepsis $(27,28)$, intestinal ischemia-reperfusion $(29,30)$, LPS- $(31,32)$, and bleomycin-induced ALI $(33,34)$. Mechanically, ghrelin attenuates the activation of NF- $\mathrm{kB}$ signaling, reduces iNOS expression, and inhibits Akt phosphorylation in kidney or brain injury $(35,36)$. However, the molecular mechanisms of ghrelin underlying ALI/ARDS need further investigated. In this study, our results demonstrate that ghrelin presents dual functions in seawater drowning induced ALI/ARDS. On one hand, ghrelin represses the NF- $\mathrm{KB}$ activation, inflammatory cytokines expression, and mitochondria injury to inhibit apoptosis of lung epithelial cells. On the other hand, the production of chemokines CXCL1 and CXCL2 are reduced after exogenous ghrelin administration both in vivo and in vitro, which leads to neutrophils recruitment decreasing and inflammatory response regulation. Therefore, the dual protective functions of ghrelin alleviate the lung injury and provide a potential therapeutic target of seawater drowning induced ALI/ARDS.

\section{Methods}

\section{Materials}

A5 49 cells were purchased from Procell Life Science\&Technology Company, DMEM (Gibco 11965092, USA), and fetal bovine serum (FBS) (Gibco 10270106, USA) were purchased from gibco company, Trypsin solution was purchased from Beyotime company (Beyotime C0204, China).

\section{Rats model}

Sprague Dawley (SD) rats (male; approximately 6 to 8 weeks old; $200 \pm 20 \mathrm{~g}$ ) were obtained from the Experimental Animal Center of Air Force Military Medical University (Xi'an, China), housed in groups of four and given five days to acclimate to the housing facility. The animals were reared under conditions of $22 \pm 2{ }^{\circ} \mathrm{C}$, the humidity of $55 \% \pm 10 \%$, light/dark cycle $=12$ hours, and ad libitum access to water and food. At the start of the experiments, animals weighed (mean \pm SD) $205 \pm 15$ grams. The in vivo experiments were performed with 10 rats, including 5 control rats injected with PBS and 5 therapeutic rats with intravenously administered 
ghrelin (10 ng/kg) according to the previous study from our partners and other groups (37-39). The animal experiments were performed under a project license (No.: 113-20200269) granted by the Animal Experiment Administration Committee of the Fourth Military Medical University, in compliance with the National Institutes of Health guidelines for care and use of Laboratory Animals [1986 (UK), amended 2013]. After administration of seawater simulants by nasal instillation, the rats were injected with PBS or ghrelin. Four days after injury, the rats were sacrificed and lung tissues were isolated for further experiments. The experimenters were blinded to the pharmacological treatment while processing data and making exclusion decisions. All sections of this report adhere to the ARRIVE Guidelines for reporting animal research (available at http://dx.doi.org/10.21037/atm21-795).

\section{Lactate debydrogenase (LDH) assay}

A549 cells were cultured in 96-well plates with different concentrations of seawater, then detected the activity of cells according to the introduction of LDH Cytotoxicity Detection Kit (Takara MK401, Japan) using the microplate reader (PR 4100 imark, USA) at $490 \mathrm{~nm}$ wavelength.

\section{TUNEL staining}

The apoptosis of A549 cells with different concentrations of seawater was detected according to the instructions of the DeadEnd ${ }^{\mathrm{TM}}$ Fluorometric TUNEL System (Promega G3250, USA). The number of apoptotic cells was counted under a fluorescence microscope.

\section{The Cell Counting Kit-8 (CCK-8) assay}

The CCK-8 assay (Beyotime C0041, China) was performed to test the proliferation of A549 cells. A549 cells were seeded in 96-well plates at a density of $10^{4}$ cells/well and cultured for $48 \mathrm{~h}$ with different concentrations of seawater. According to the CCK8 assay kit, $10 \mu \mathrm{L} /$ well of the CCK-8 reaction solution was added to the plates by incubating for $2 \mathrm{~h}$. Then the optical density (OD) value was measured at $450 \mathrm{~nm}$ wavelength by a microplate reader.

\section{Immunofluorescent staining}

A549 cells were seeded in 24-well plates with slides at a density of $10^{5}$ cells/well and cultured for $48 \mathrm{~h}$ with different concentrations of seawater. The cells on slides were fixed with $4 \%$ paraformaldehyde (PFA) solution for $20 \mathrm{~min}$ and blocked with $1 \%$ bovine serum albumin (BSA) for $15 \mathrm{~min}$, then incubated with Ki67 antibody (Abcam 15580, UK) overnight at $4{ }^{\circ} \mathrm{C}$. Next, the cells were incubated with a secondary antibody (Abcam 150081, UK) for $2 \mathrm{~h}$ at room temperature, and stained with Hoechst (Sigma-Aldrich, 14533). The number of positive cells was counted under a fluorescence microscope.

\section{Flow cytometry}

The cells which were treated in different ways were collected and fixed with 70\% ethanol overnight. Then cells were stained with propidium iodide (PI) (Beyotime ST511, China), and were detected with flow cytometry to obtain the apoptosis rate and cell cycle distribution.

\section{Western blotting}

Total cell proteins were extracted using RIPA lysis buffer (Beyotime P0013B, China), when A549 cells had been treated for $48 \mathrm{~h}$ with a different approach. SDS-PAGE (ZHOGNHUIHECAI JC-PE022, China) was performed in running buffer at $220 \mathrm{~V}$ for $45 \mathrm{~min}$. Proteins on gels were transferred to polyvinylidene fluoride (PVDF) membrane (Merck Millipore IPVH00010, USA) at $100 \mathrm{~V}$ for $2 \mathrm{~h}$. Then the PVDF membrane was blocked in non-fat milk and subsequently incubated with primary antibodies overnight at $4{ }^{\circ} \mathrm{C}$. The next day, the secondary antibodies were incubated for $2 \mathrm{~h}$ at room temperature. The protein level on the PVDF membrane was detected with the enhanced chemiluminescence (ECL) reagent kit (Millipore WBKLS0100, USA). The primary antibodies included NF-kB p65 (D14E12) XP ${ }^{\circledast}$ Rabbit mAb (HRP Conjugate) (1:1,000, CST 59674S, USA), Phospho-NF-кB p65 (Ser536) (93H1) Rabbit mAb (1:1,000, CST 3033S, USA), p44/42 MAPK (Erk1/2) Antibody (1:1,000, CST 9102S, USA), Phospho-p44/42 MAPK (Erk1/2) (1:1,000, CST 8544S, USA), Caspase-3 Antibody (1:1,000, CST 9662S, USA), Bcl-2 (124) Mouse mAb (1:1,000, CST 15071S, USA), Phospho-Akt (Ser473) (D9E) Rabbit mAb (1:1,000, CST 4060S, USA), and $\beta$-actin Mouse mAb $(1: 1,000$, CST 3700S, USA). The secondary antibodies included Peroxidase AffiniPure Goat Anti-Mouse IgG $(\mathrm{H}+\mathrm{L})$ (1:10,000, YEASEN 33201ES60, China) and PeroxidaseConjugated Goat Anti-Rabbit IgG (H+L) (1:10,000, YEASEN 33101ES60, China). 


\section{ATP determination assay}

A549 cells were cultured in 6-well plates with different treatment ways for $24 \mathrm{~h}$. And the medium was removed to lyse the cells completely with lysis buffer and centrifuged to collect the supernatant. The supernatant was measured according to the introduction of the ATP Assay Kit (Beyotime S0026, China).

\section{2',7'-Dichlorofluorescein diacetate (DCFH-DA) assay}

A549 cells in the logarithmic growth phase were inoculated into 96 -well plates with $4 \times 10^{5}$ cells/mL and treated by different concentrations of seawater. The cells were incubated with $100 \mu \mathrm{L}$ DCFH-DA (Sigma-Aldrich 35845, USA) at a concentration of $10 \mathrm{mmol} / \mathrm{L}$ for $30 \mathrm{~min}$ after cultured $24 \mathrm{~h}$. The fluorescence intensity standing for the ROS level was detected using a microplate reader.

\section{Enzyme-linked immunosorbent assay (ELISA)}

After $48 \mathrm{~h}$ of different treatment for the A549 cells, the cell culture medium of each group was collected and centrifuged followed the instruction of the ELISA kit (R\&D Systems DYC4198-5, USA). Then the OD value of proteins was measured by a microplate reader and received the data.

\section{Quantitative real-time polymerase chain reaction ( $q R T-P C R$ )}

Total RNA was extracted using TRIzol (Invitrogen 10296010, USA) method, and reversed to cDNA using the PrimeScript ${ }^{\text {TM }}$ RT reagent Kit (Takara RR037A, Japan). The The qRT-PCR process using TB Green ${ }^{\circledR}$ Premix Ex Taq ${ }^{\text {TM }}$ (Takara RR420A, Japan). The primer sequences were as follows: CXCL1Forward: 5'-TGCTGCCACTAATGCTGATGT-3', CXCL1Reverse: 5'-CTCAGGAACCAATCTTTGCACT-3'; CXCL2-Forward: 5'-TGCTGCCACTAATGCTGATGT-3', CXCL2-Reverse: 5'-CTCAGGAACCAATCTTTGCACT-3'; CCL2-Forward: 5'-CATCTCCTACACCCCACGAAG-3', CCL2-Reverse: 5'- GGGTTGGCACAGAAACGTC-3'; CCL5-Forward: 5'-CCAGCAGTCGTCTTTGTCAC-3', CCL5-Reverse: 5'-CTCTGGGTTGGCACACACTT-3'; TNF- $\alpha$-Forward: 5 '-CGGCTACCTAGTCTACGCC-3', TNF- $\alpha$-Reverse: 5'-AAGTCGCCGCCAATGTTGA-3'; IL1 $\beta$-Forward: 5'-CCAGCAGTCGTCTTTGTCAC-3', IL1 $\beta$-Reverse: 5'-CTCTGGGTTGGCACACACTT-3'; IL6-Forward: 5'-CCAGCAGTCGTCTTTGTCAC-3', IL-6Reverse: 5'-CTCTGGGTTGGCACACACTT-3'; $\beta$-actinForward: 5'-CCAGCAGTCGTCTTTGTCAC-3', $\beta$-actin-

\section{Reverse: 5'-CTCTGGGTTGGCACACACTT-3'.}

\section{Transwell assay}

The invasion of cancer cells was determined with a Matrigelcoated (BD Biosciences) Transwell assay. The upper chamber was coated with $100 \mathrm{~mL}$ diluted Matrigel. After $24 \mathrm{~h}$ of transfection, $2 \times 3 \times 10^{4}$ cells with FBS-free DMEM were transferred to the upper chamber, and the complete medium was added to the lower chamber. After $24 \mathrm{~h}$, the invasive cells were fixed with $4 \%$ paraformaldehyde, then stained with $0.1 \%$ crystal violet. The number of invasive cells was counted under a microscope. Each experiment was performed in triplicate.

\section{Hematoxylin-eosin staining}

The rat lung tissue samples were routinely embedded in paraffin, then cut into slices with the thickness of 5-8 $\mu \mathrm{m}$, subsequently soak in $40{ }^{\circ} \mathrm{C}$ warm water and dry in the incubator. The slices were put into dimethylbenzene for $10 \mathrm{~min}$ and repeat once again for dewaxing. The treated tissue is hydrated by high to low concentration alcohol and finally into distilled water. Then the samples were incubated with hematoxylin staining solution for 5-10 min (Sangon biotech E607317, China), then rinse in distilled water, differentiate with $0.1 \%$ hydrochloric acid-ethanol, and rinse in distilled water again. Afterward, the samples were stained with the eosin solution and dehydrated with different concentrations of alcohol. The slices were put into dimethylbenzene twice, and after drying mounted for observation under a microscope.

\section{Statistical analysis}

Statistical analysis was performed with the GraphPad Prism 8.0 software. All data were presented as the mean \pm standard error of mean (SEM). Differences between the two groups were compared using unpaired Student's $t$-test (2 tailed), and differences between multiple groups were compared using oneway ANOVA. $\mathrm{P}<0.05$ was considered statistically significant.

\section{Results}

\section{Ghrelin rescued the apoptosis promotion and proliferation inbibition function of seawater in vitro}

Seawater drowning often induces excessive inflammatory response and then results in serious lung injury, which is 

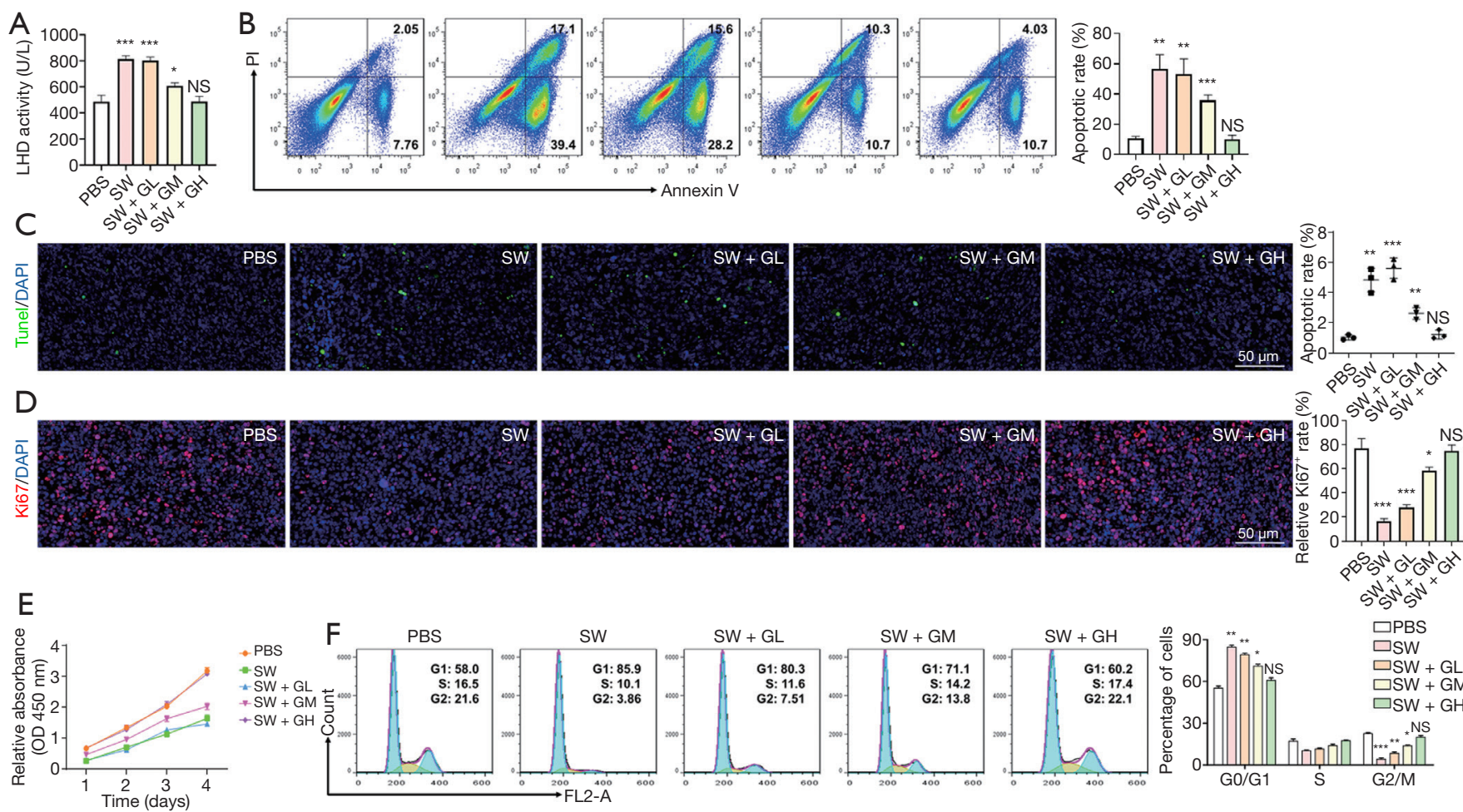

Figure 1 Ghrelin has a therapeutic effect on seawater induced apoptosis of A549 cells. (A) A549 cells were treated with seawater simulants (SW) or phosphate buffer saline (PBS), followed by incubation of ghrelin with different concentrations [ghrelin-low (GL), $10 \mathrm{nM}$; ghrelinmid (GM), $50 \mathrm{nM}$; ghrelin-high (GH), $100 \mathrm{nM}$ ]. Then the cytotoxicity of A549 cells was assessed by lactate dehydrogenase (LDH) activity determination $(n=6)$. (B,C) A549 cells were treated as same as (A) and the apoptosis was evaluated by FACS (B) (n=6) and TdT-mediated dUTP nick end labeling (TUNEL) staining (C) (n=6). (D-F) A549 cells were treated as same as (A) and the proliferation was determination by Ki67 staining (D) (n=6), CCK-8 assay $(\mathrm{E})(\mathrm{n}=6)$ and cell cycle detect $(\mathrm{F})(\mathrm{n}=6)$. Bars, means \pm standard error of mean $(\mathrm{SEM}) ;$ * $\mathrm{P}<0.05$; **, $\mathrm{P}<0.01 ;$ ***, $\mathrm{P}<0.001$; ns, not significant.

the main cause of seawater drowning-induced death $(2,3)$. Previous literatures have pointed out that ghrelin plays a role in alleviating the progression of multiple inflammatory diseases (40-42). Therefore, in vitro experiments were used to verify the effect of ghrelin on lung epithelial cell damage caused by seawater exposure. We incubated A549 cells with PBS or simulated seawater respectively, and added exogenous ghrelin with different concentrations. After 6 hours, the LDH activity of A549 cells was detected. The results suggested that simulated seawater significantly enhanced the LDH activity of A549 cells. At the same time, although the low concentration of ghrelin did not affect the increase of LDH activity induced by simulated seawater, medium and high concentration of ghrelin significantly inhibited the regulation of simulated seawater on the LDH activity, especially high concentration of ghrelin restored the LDH activity to the quiescent level of PBS control group (Figure 1A). Furthermore, we used flow cytometry to detect the cell apoptosis affected by simulated seawater or/ and ghrelin. As expected, simulated seawater dramatically promoted the apoptosis of A549 cells, while medium and high concentrations of ghrelin alleviated the pro-apoptotic effect of simulated seawater in different degrees (Figure 1B). TUNEL staining also showed that the apoptosis promoting effect mediated by simulated seawater could be completely rescued by a high concentration of ghrelin (Figure 1C).

Next, we detected the proliferation of A549 cells after simulated seawater and/or ghrelin stimulation by using Ki67 staining and CCK8 assay. The results indicated that ghrelin retrieved the proliferation repression mediated by seawater simulants in a dosage-dependent manner (Figure 1D,E). Further cell cycle analysis showed that seawater simulants could block the cell cycle of A549 cells at G0 phase, while the high concentration of ghrelin accelerated A549 cells 

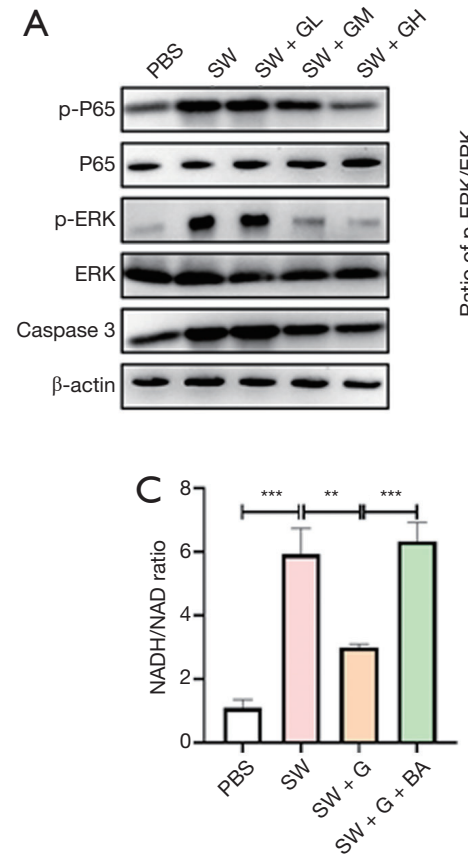
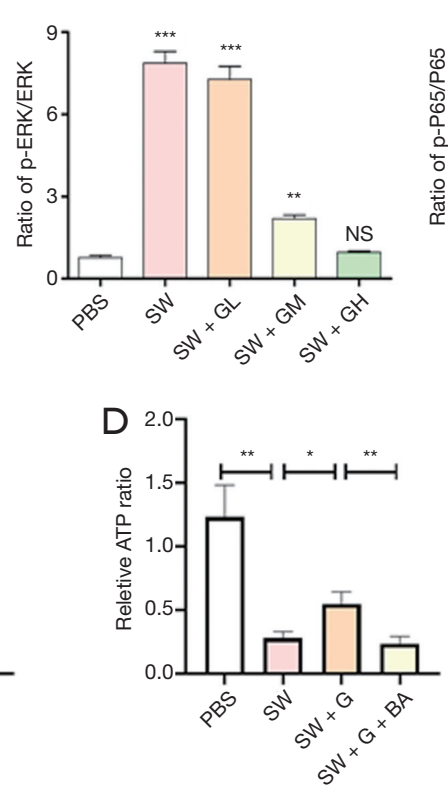
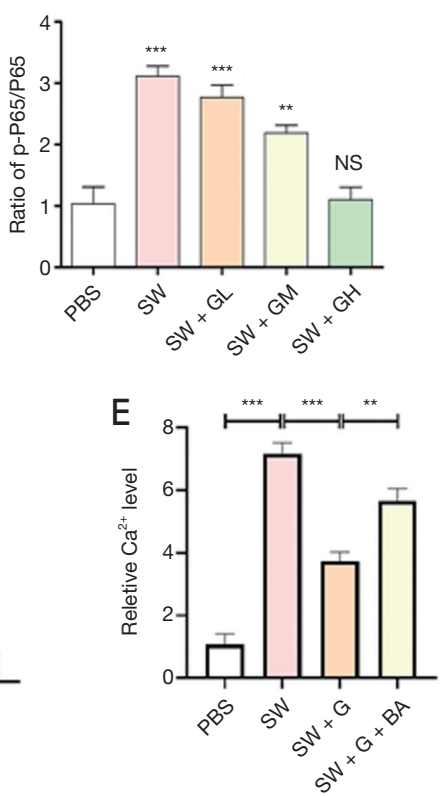

B
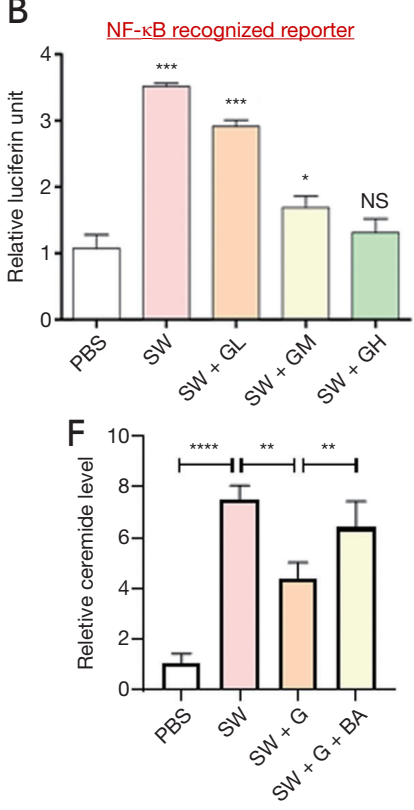

Figure 2 Ghrelin regulates mitochondrial damage in A549 cells through NF- $\kappa$ B pathway. (A) A549 cells were treated with different concentrations of ghrelin, and the expression level of NF- $\kappa$ B associated proteins was assessed by Western blot (WB) (n=6). (B) The reporter system was constructed by inserting a fragment containing $\mathrm{NF}-\kappa \mathrm{B}$ recognized motif upstream to luciferase. Then reporter gene assay was performed to evaluate the activation of NF- $\kappa$ B signaling $(n=6)$. (C-F) A549 cells were incubated with seawater simulants and a high concentration of ghrelin with or without NF- $\kappa$ B agonist (Betulinic acid, BA, USA). And the function of mitochondria was evaluated by reduced nicotinamide adenine dinucleotide $(\mathrm{NADH}) / \mathrm{NAD}$ ratio detection $(\mathrm{C})(\mathrm{n}=6)$, Adenylate triphosphate $(\mathrm{ATP})$ generation testing $(\mathrm{D})$ $(\mathrm{n}=6)$ and concentration of intracellular calcium $(\mathrm{E})(\mathrm{n}=6)$ and ceremide determination $(\mathrm{F})(\mathrm{n}=6)$. Bars, means $\pm \mathrm{SEM}$; * $\mathrm{P}<0.05 ;{ }^{* *}, \mathrm{P}<0.01$; ***, $\mathrm{P}<0.001 ;{ }^{* * * *}, \mathrm{P}<0.0001$. ns, not significant.

entering into G2 phase again (Figure $1 F$ ). The above results demonstrated that seawater simulants promoted the apoptosis and inhibited the proliferation of A549 cells, and ghrelin incubation significantly rescue the function of seawater simulants and alleviate the damage degree of A549 cells.

\section{Ghrelin modulated mitochondria damage of A549 cells via NF- $\boldsymbol{B} B$ signaling}

Next, we explored the molecular mechanisms of ghrelin regulating lung epithelial cell damage induced by seawater simulants. It has been reported that seawater drowning would lead to rapid and effective activation of NF- $\kappa \mathrm{B}$ signaling pathway in lung tissue (13). Additionally, ghrelin is involved in the interference of many inflammatory signals, including NF- $\mathrm{KB}$ pathway and STATs signaling $(12,13,16)$. Therefore, we detected the expression of NF$\kappa \mathrm{B}$ downstream molecules in A549 cells with different treatments. The results of $\mathrm{WB}$ showed that seawater simulants promoted the phosphorylation of $\mathrm{P} 65$ and ERK, which are the hallmarks of activated NF- $\mathrm{kB}$ pathway. When ghrelin was co-incubated with A549 cell as well as seawater simulants, P65 and ERK signaling were gradually inhibited to normal level (Figure 2A). Meanwhile, we constructed the reporter system with NF- $\mathrm{BB}$ recognition motif, which could reflect the activation of NF- $\mathrm{KB}$ pathway by the intensity of luciferin. The reporter assay indicated that the activity of $\mathrm{NF}-\kappa \mathrm{B}$ pathway was elevated by seawater simulants greatly, while was repressed by ghrelin, which is consistent with the conclusion of WB (Figure 2B). These results suggest that ghrelin inhibited the activation of NF- $\mathrm{BB}$ signaling pathway mediated by seawater simulants.

Previous reports indicated that the excessive NF$\kappa \mathrm{B}$ signaling activation led to mitochondria damage and affected cell survival (43). Therefore, we evaluated the mitochondrial function by detecting NADPH consumption and ATP generation. The results suggested that the ratio of NADPH/NADP increased and ATP production decreased 
in A549 cells treated with seawater simulants. After administration of ghrelin, the levels of NADPH and ATP were restored. Interestingly, the rescue function of ghrelin was counteracted with the triggering of NF- $\mathrm{KB}$ signaling by an agonist, indicating that ghrelin could regulate mitochondrial dysfunction by interfering with the activation of NF- $\kappa \mathrm{B}$ by seawater simulants (Figure $2 C, D$ ). The increase of calcium concentration and ceramide synthesis are the important hallmarks of mitochondrial damage. Therefore, we measured the concentration of calcium and ceramide in lung epithelial cells after different treatments. The results showed that seawater simulants increased intracellular calcium concentration and ceramide accumulation, and were rescued by ghrelin incubation via an NF- $\mathrm{KB}$ signaling dependent pathway (Figure 2E,F). These results suggest that ghrelin protected lung epithelial cells from mitochondrial damage induced by seawater simulants by regulating NF- $\mathrm{KB}$ signaling pathway.

\section{Ghrelin protected A549 cells from apoptosis mediated by seawater simulants by inbibiting NF- $\mathrm{KB}$ signaling}

Generally, the mitochondria damage would induce ROS generation, and then results in cell apoptosis. Therefore, we detected the expression of apoptosis-associated proteins, indicating that ghrelin repressed the apoptosis promotion effect of seawater simulants via inhibiting NF- $\mathrm{KB}$ signaling (Figure $3 A$ ), which was consistent with the modulation of mitochondria function. Expectedly, the ROS production elevated by seawater simulants was eliminated after ghrelin treating. While NF- $\mathrm{BB}$ signaling inhibitor rescued the therapeutic effect of ghrelin (Figure $3 B$ ). The further phenotype detection indicated that ghrelin indeed retrieved the apoptosis promotion (Figure $3 C, D$ ) and proliferation inhibition (Figure $3 E, F$ ) function of seawater simulants by blocking NF- $\mathrm{kB}$ signaling. The above results demonstrated that NF- $\mathrm{\kappa B}$ dependent mitochondrial damage induced by seawater simulants initiated the apoptosis signal of A549 cells, which could be recovered by ghrelin administration.

\section{Ghrelin regulated the paracrine pathway of injured lung epithelial cells to affect neutrophils development and immune response by inbibiting $\mathrm{NF}-\kappa \mathrm{B}$ patbway}

A lot of evidence corroborated that activated NF$\kappa \mathrm{B}$ pathway induces inflammatory response (44). We detected the expression of cytokines and chemokines after seawater and ghrelin treatment. The results of ELISA assay suggested that seawater simulants increased the production of inflammatory cytokines and were retrieved by ghrelin. When NF- $\mathrm{NB}$ signaling was activated by an agonist, the effect of ghrelin was restrained (Figure 4A). Many inflammatory factors could regulate immune cells development. It has been reported that COX and PEG2 promoted neutrophils generation and function. The further determination demonstrated that ghrelin inhibited the production of COX and PEG2 induced by seawater simulants relying on NF- $\kappa \mathrm{B}$ signaling blockade (Figure $4 A, B$ ). In addition, the chemokines responsible for neutrophils recruitment, including CXCL1 and CXCL2, were also increased by seawater simulants and reduced by ghrelin without constitute NF- $\mathrm{KB}$ activation (Figure $4 C$ ). However, the expression of CCL2 and CCL5, which mediated monocytes and macrophages infiltration, was not affected after seawater simulants triggering (Figure 4D).

Considering that seawater regulated the expression of neutrophils development associated factors, the Transwell, and FACS assay were performed to evaluate the effect of ghrelin on neutrophils recruitment and generation. Although seawater simulants accelerated neutrophils migration and differentiation, additional ghrelin dramatically suppressed the function of seawater simulants dependent on NF- $\kappa \mathrm{B}$ inhibiting (Figure $5 A, B)$. Meanwhile, ghrelin reduced the ROS generation (Figure $5 C$ ) and inflammatory cytokines production (Figure $5 D$ ) mediated by activated neutrophils. The above results showed ghrelin reduced the secretion of cytokines and chemokines regulating neutrophils development by inhibiting NF-kB pathway.

\section{Ghrelin presented a protective effect on lung injury induced by seawater drowning}

Next, the function of ghrelin on immune repression was evaluated by rat seawater drowning model. At the start of the experiments, animals were healthy and weighed (mean \pm SD) $205 \pm 15$ grams. After administration of seawater simulants by nasal instillation, the rats were injected with PBS or ghrelin ( $\mathrm{n}=5$ PBS versus $\mathrm{n}=5$ Ghrelin). Four days after injury, the rats were sacrificed and lung tissues were isolated for further experiments. The dry and wet weight ratio of lung tissue was increased after ghrelin therapy, suggesting ghrelin improved the pulmonary edema induced by seawater drowning (Figure $6 A$ ). The results of HE staining showed that the alveolar structure of drowning rats was destroyed compared with healthy rats, while ghrelin administration retrieved the lung tissue 

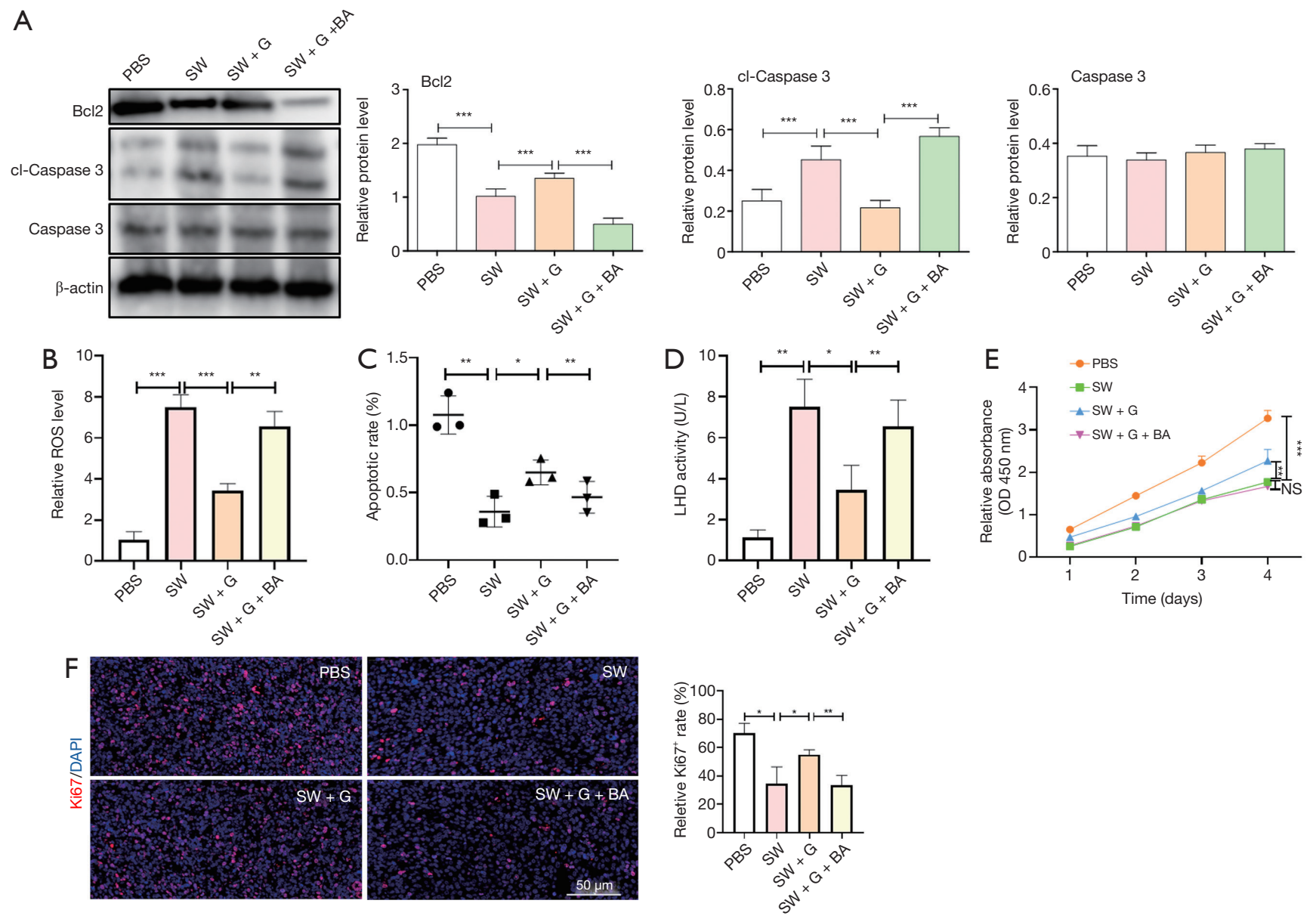

Figure 3 Ghrelin protected A549 cells from apoptosis mediated by seawater simulants by inhibiting NF- $\kappa \mathrm{B}$ signaling. (A-D) A549 cells were treated with seawater simulants and rescued by ghrelin with or without NF- $\kappa$ B agonist (BA). The expression of Bcl2 and Caspase3 was detected by WB (A) (n=5), and ROS generation was determined by Fluorescence activated Cell Sorting (FACS) and the relative mean fluorescence intensity (MFI) was calculated and compared (B) $(n=5)$. The apoptosis of A549 cells was evaluated by PI/AnnexinV staining (C) $(n=3)$ and LDH activity detection (D) (n=3). (E,F) The A549 cells were treated as same as (A) and the cell proliferation was detected by Cell Counting Kit (CCK)-8 assay $(\mathrm{E})(\mathrm{n}=6)$ and Ki67 staining $(\mathrm{F})(\mathrm{n}=5)$. Bars, means $\pm \mathrm{SEM} ;{ }^{*}, \mathrm{P}<0.05 ;{ }^{* *}, \mathrm{P}<0.01 ;{ }^{* * *}, \mathrm{P}<0.001 ; \mathrm{ns}, \mathrm{not}$ significant.

structure to some extent (Figure 6B). The MPO staining result indicated that the infiltrating of neutrophils was reduced after ghrelin treatment (Figure 6C). Expectedly, the mRNA and protein levels of CXCL1 and CXLC2 in lung tissue were both repressed by ghrelin (Figure 6D,E). In addition, the expression of inflammatory cytokines (Figure $6 F, G$ ) and ROS production (Figure $6 H$ ) were decreased by therapy of ghrelin. Mechanically, ghrelin also inhibited the activation of NF- $\mathrm{KB}$ signaling in vivo (Figure 6I). The above data demonstrated that ghrelin significantly attenuated the inflammatory response and alleviated the lung injury induced by seawater drowning in vivo.

\section{Discussion}

Seawater inhalation lung injury is a systemic inflammatory response syndrome, which is mostly caused by seawater drowning. Without timely intervention, it may soon develop into seawater inhalation ARDS, with a mortality rate of more than $80 \%(2,3)$. Therefore, it is of great significance to understand the mechanism of seawater inhalation lung injury for finding treatment strategies. Because the composition of seawater is too complex, different components will cause different damage mechanisms. The lung injury caused by seawater drowning often has the characteristics of mixed 

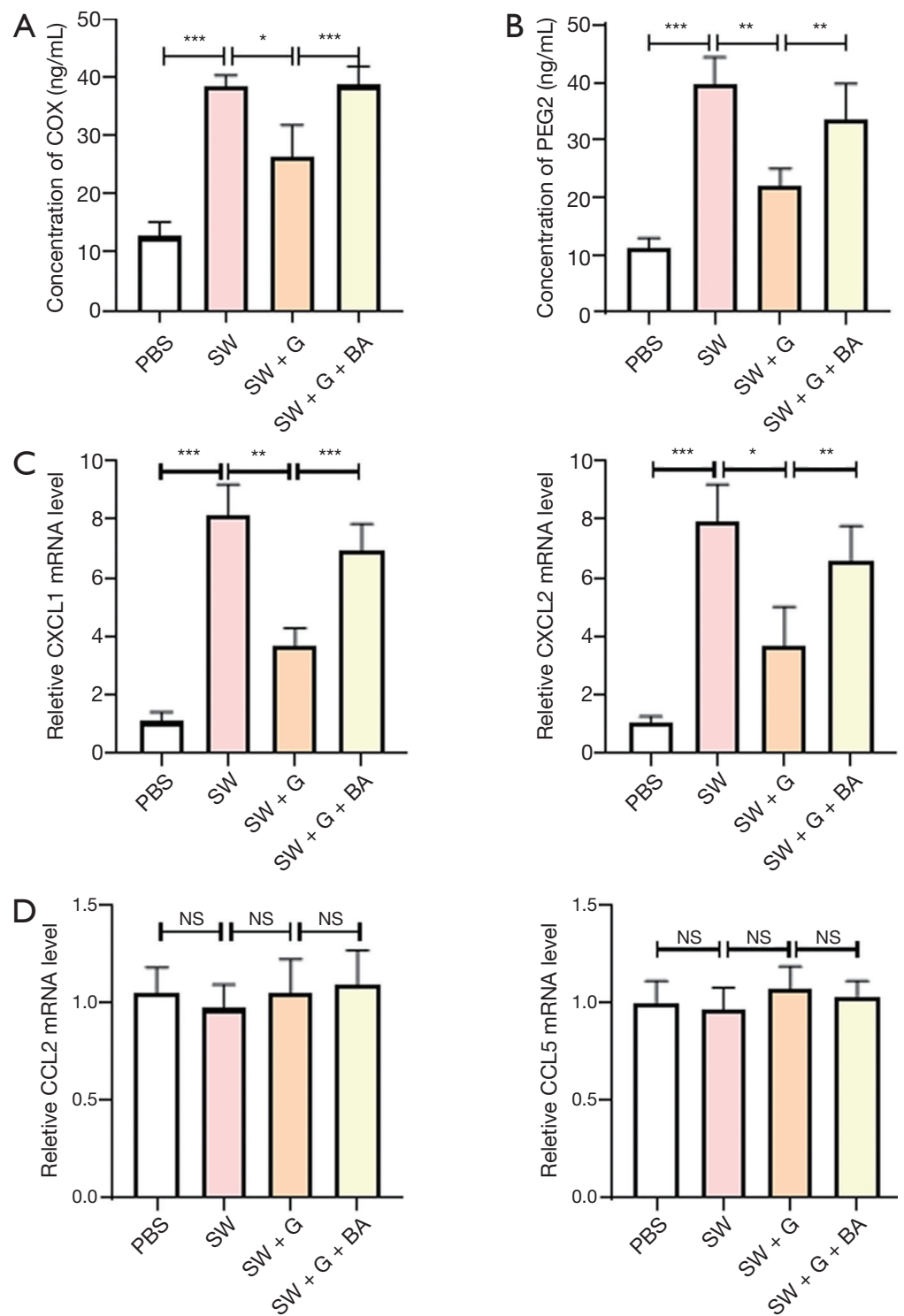

Figure 4 Ghrelin regulated the cytokines and chemokines production by injured lung epithelial cells. (A-D) After A549 cells were treated with seawater simulants and rescued by ghrelin with or without NF- $\kappa \mathrm{B}$ agonist (BA). Then enzyme linked immunosorbent assay (ELISA) and quantitative Real-Time PCR (qRT-PCR) assay were performed to determine the expression of inflammatory mediators COX and PGE2 $(\mathrm{A}, \mathrm{B})(\mathrm{n}=5)$, neutrophils chemokines C-X-C motif chemokine ligand 1 (CXCL1) and C-X-C motif chemokine ligand 2 (CXCL2) (C) (n=5) and macrophages chemokines $\mathrm{C}-\mathrm{C}$ motif chemokine ligand 2 (CCL2) and C-C motif chemokine ligand 5 (CCL5) (D) (n=5). Bars, means \pm SEM; * $\mathrm{P}<0.05 ;$ **, $\mathrm{P}<0.01$; ***, $\mathrm{P}<0.001$; ns, not significant.

etiology. Among them, heavy metal ions induce DNA damage and mitochondrial dysfunction, and then cause apoptosis and necrosis of lung epithelial cells (1). This is also the main reason for the decrease of alveolar ventilation after seawater drowning. In the past, the main treatment strategies were a combination of respiratory assistance, supportive treatment, and prophylactic antibiotic administration, which can ensure the normal oxygen supply of the body, and prevent the secondary damage caused by the activation of the inflammatory response to play the role of cell protection $(1,45)$. However, the expression or activation intervention of apoptosis-related molecules cannot essentially block the source of the damage, such as the cytotoxicity caused by ions and reactive oxygen species $(8,10)$. On the other hand, the 
A
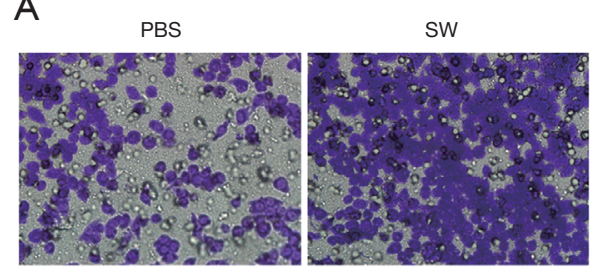

$\mathrm{SW}+\mathrm{G}$

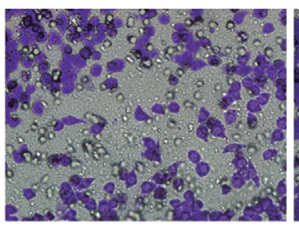

$\mathrm{SW}+\mathrm{G}+\mathrm{BA}$

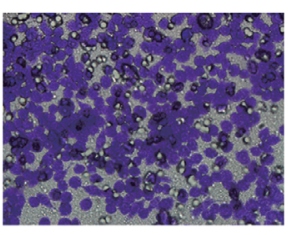

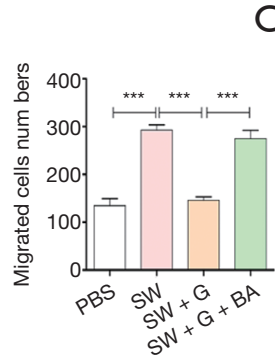
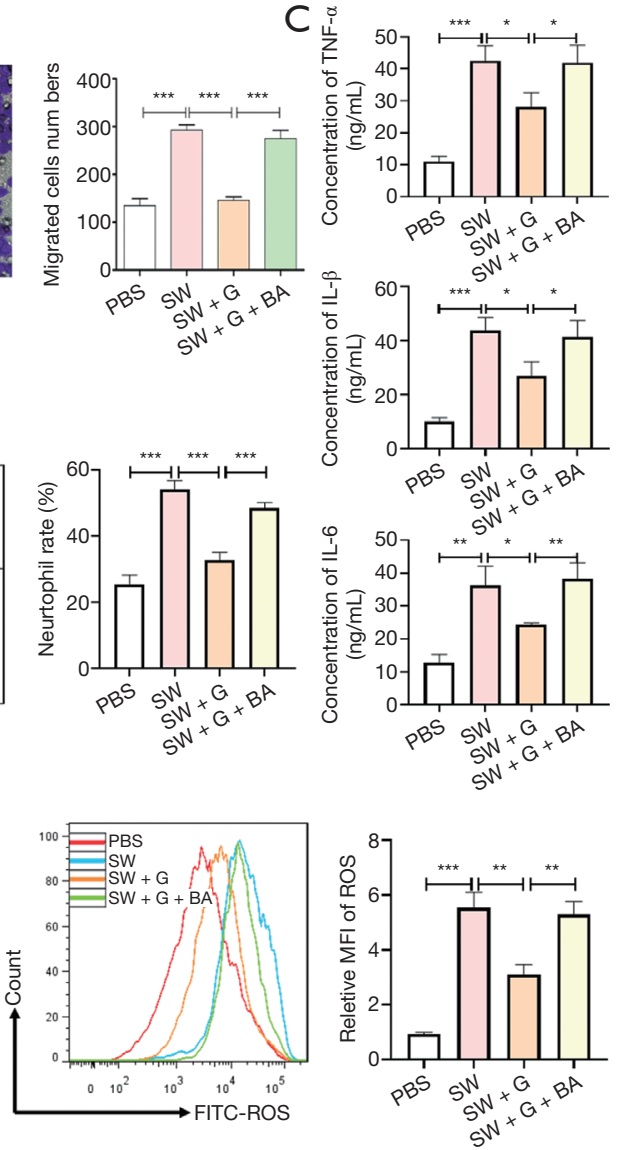

B

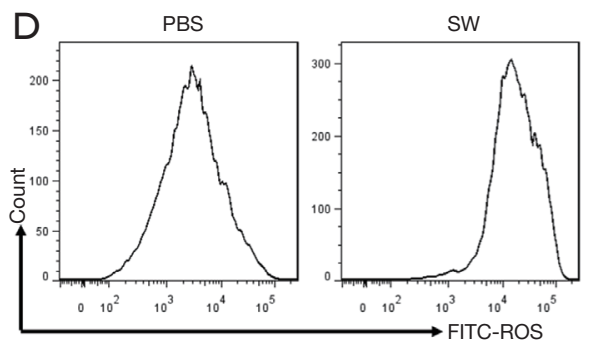

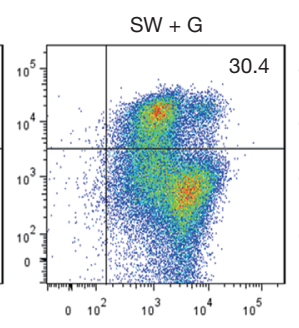
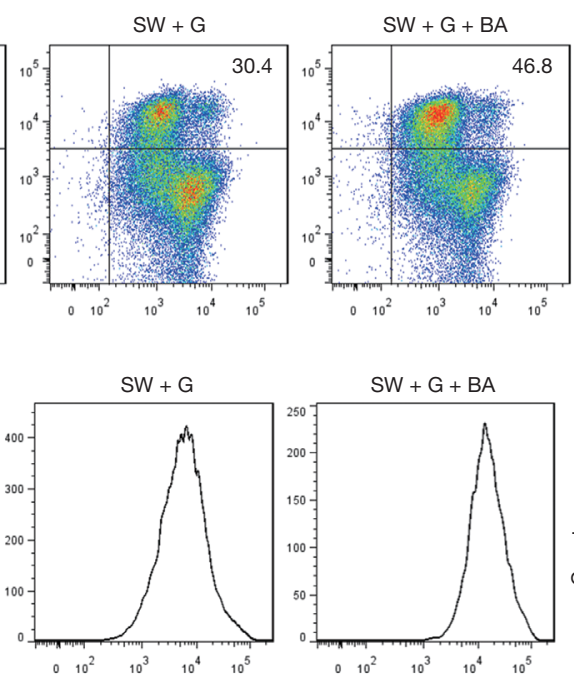

Figure 5 Ghrelin regulated the paracrine pathway of lung epithelial cells to affect neutrophils recruitment and development via inhibiting NF- $\kappa \mathrm{B}$ signaling. (A) Sorted neutrophils from bone marrow (BM) were seed into the upper chamber of the Transwell plate, and A549 cells with different treatments were cultured in the lower wells. The cells were incubated for 12 hours and the migration rate of neutrophils was assessed ( $n=5)$. (B) A549 cells were treated as same as (A) and the supernatant was collected to incubate BM cells with granulocytemacrophage colony stimulating factor (GM-CSF) $(25 \mathrm{ng} / \mathrm{mL})$ stimulation for 3 days. Then the differentiation of neutrophils (B) (n=5), the cytokines production (C) $(n=5)$ and reactive oxygen species (ROS) generation (D) $(n=5)$ were determined to evaluated the functions of neutrophils. Bars, means $\pm \mathrm{SEM} ;{ }^{*}, \mathrm{P}<0.05 ;{ }^{* *}, \mathrm{P}<0.01$; ${ }^{* * *}, \mathrm{P}<0.001$; ns, not significant.

use of corticosteroids and other hormones for intervention therapy, although to a certain extent, could well inhibit the immune response, reduce the inflammatory response, thus play a role in promoting the repair of damaged tissue $(46,47)$. However, continuous administration would result in systemic immunosuppressive effect, and cause novel infections, hyperglycemia, gastrointestinal bleeding, and other adverse reactions $(46,47)$. Therefore, it is critical to find medicine or therapeutic methods with mild effects, strong adaptability, and small side effects for lung injury caused by seawater drowning.

Ghrelin is a hormone secreted by the human body, also known as the hunger hormone. Most ghrelin is generated by gastric fundus cells, and a small part is expressed and released by other digestive organs including the small intestine (40-42). In vivo, starvation or gastric food emptying will stimulate the digestive system to secrete a large amount of ghrelin. High levels of ghrelin influence the hypothalamus, thereby enhancing individual appetite. At the same time, ghrelin can also regulate the endocrine function and prevent depression after acting on the central nervous system $(48,49)$. Recent studies have shown that ghrelin can regulate glucose and lipid metabolism by inhibiting insulin level in vivo $(50,51)$. Interestingly, as a biological protective agent of physiological expression, ghrelin has strong antioxidant and immunomodulatory effects. It has a 

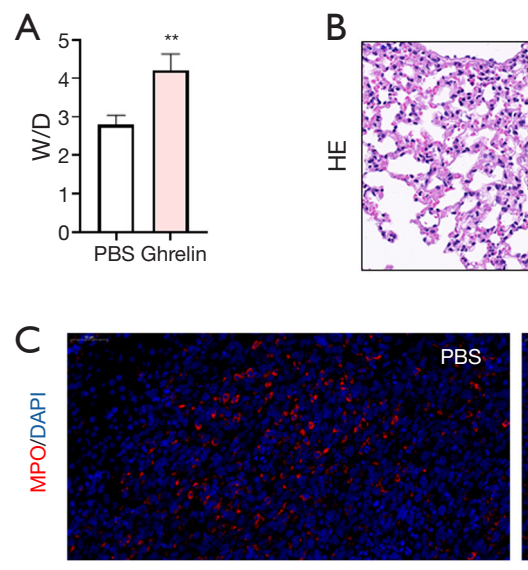

Normal
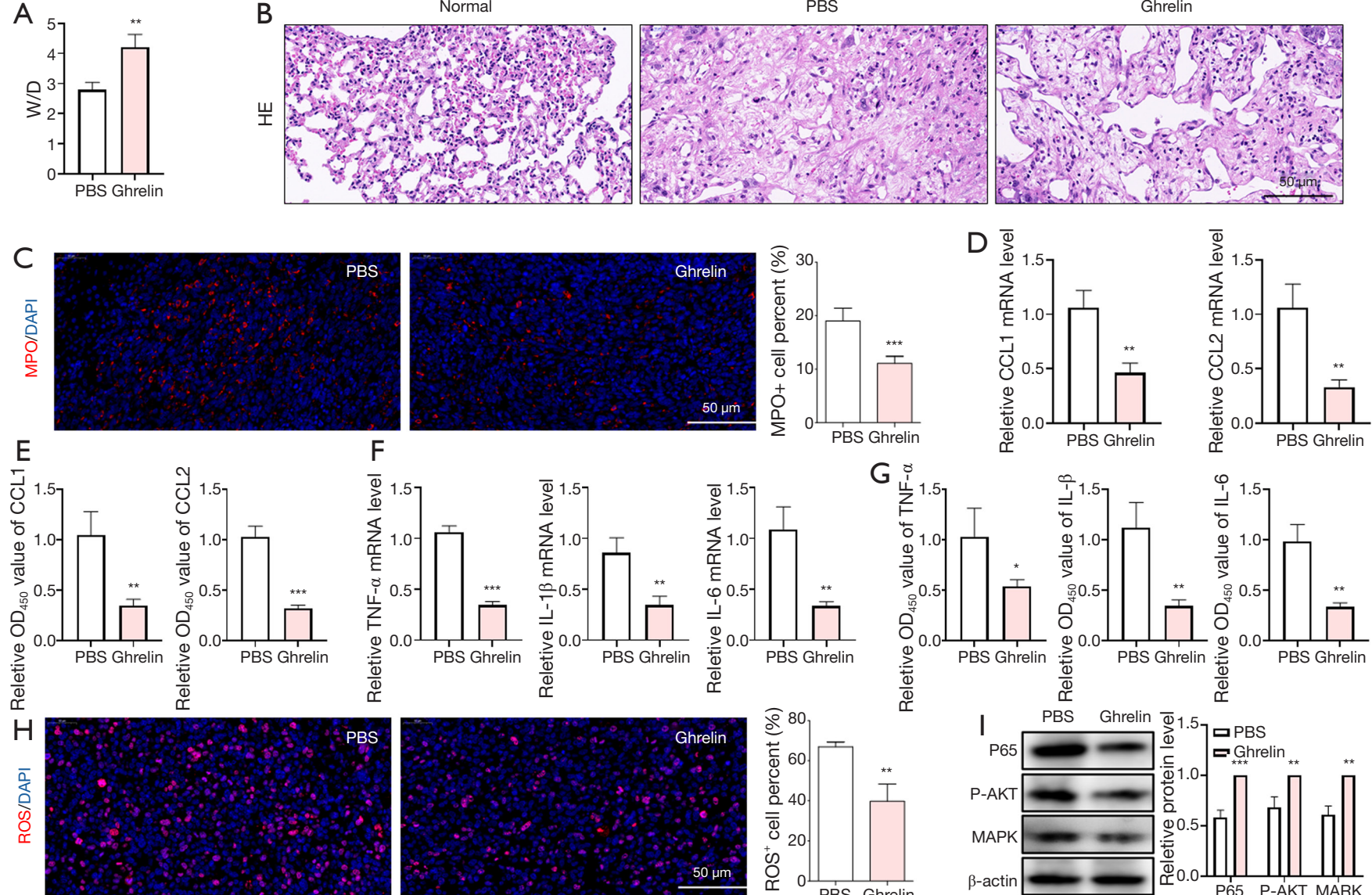
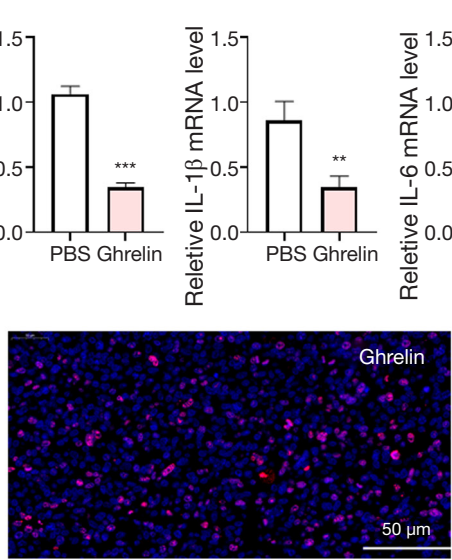

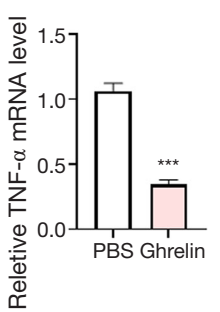

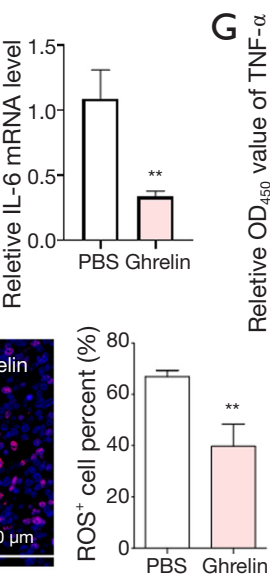
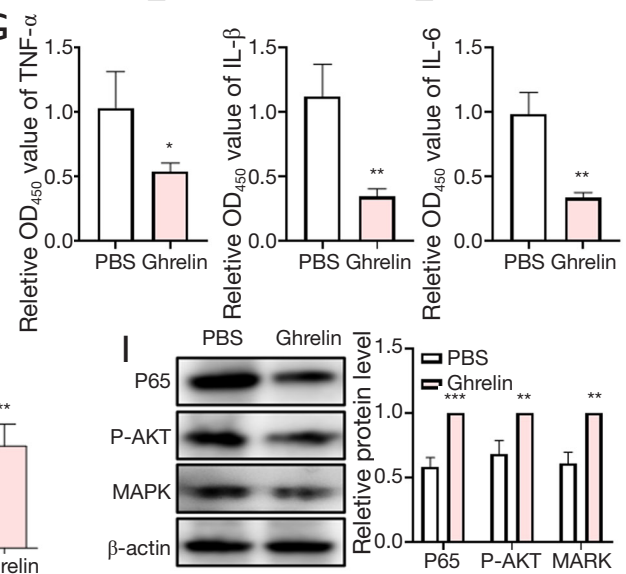

Figure 6 Ghrelin presented a protective effect on lung injury induced by seawater drowning. (A,B,C) The model of seawater drowning induced injury was established in rats, and PBS or ghrelin was injected into tail vein. The dry and wet weight ratio of lung tissue was detected (A) (n=5). Hematoxylin-eosin (HE) staining was used to observe the structure of alveolar tissue (B) (n=5). Myeloperoxidase (MPO) staining was performed to detect neutrophil infiltration $(\mathrm{C})(\mathrm{n}=5)$. (D,E,F,G) The expression levels of chemokines CXCL1 and CXCL2 (D,E) $(\mathrm{n}=5)$ and cytokines TNF- $\alpha$, IL-1 $\beta$ and IL-6 (F,G) $(n=5)$ were detected by qRT-PCR and ELISA. (H) The ROS generation was stained by using immunofluorescence ( $\mathrm{n}=5$ ). (I) The protein levels of $\mathrm{p} 65$, p-Akt and mitogen-activated protein kinase (MAPK) were detected by WB $(\mathrm{n}=5)$. Bars, means $\pm \mathrm{SEM} ;{ }^{*}, \mathrm{P}<0.05 ;{ }^{* *}, \mathrm{P}<0.01 ;{ }^{* * *}, \mathrm{P}<0.001 ;$ ns, not significant.

good scavenging function for reactive oxygen species, and presents a protective effect on injured tissues $(52,53)$. At the same time, ghrelin also alleviates the mitochondrial damage caused by the inflammatory response. In the process of pathogen infection and endotoxemia, a large number of inflammatory factors are produced. Ghrelin can inhibit the expression of inflammatory cytokines such as IL-1 $1 \beta$, IL-6 and TNF- $\alpha$ through its specific receptor pathway with a significant dosage- and time-dependent manner, which has a good protective effect on sepsis and secondary multiple organ failure (54). The protective effect of ghrelin on the stomach is also mainly achieved by inhibiting the secretion of a variety of cytokines. It can repress the activation of
$\mathrm{NF}-\kappa \mathrm{B}$ signal, reduce the inflammatory injury, accelerate the healing of gastric mucosal injury induced by ischemiareperfusion, and reduce the radiation-induced gastric mucosal inflammation and anorexia (55). In addition, further evidence for the anti-inflammatory effect of ghrelin comes from the study of a variety of autoimmune diseases. In the animal model of arthritis, recombinant ghrelin or its agonist significantly suppresses the production of IL-6 and NO by macrophages and thus alleviates arthritis $(56,57)$. However, whether ghrelin has a certain therapeutic effect on lung injury caused by seawater drowning has not been reported, and the detailed molecular mechanism of ghrelin remains to be further studied. 


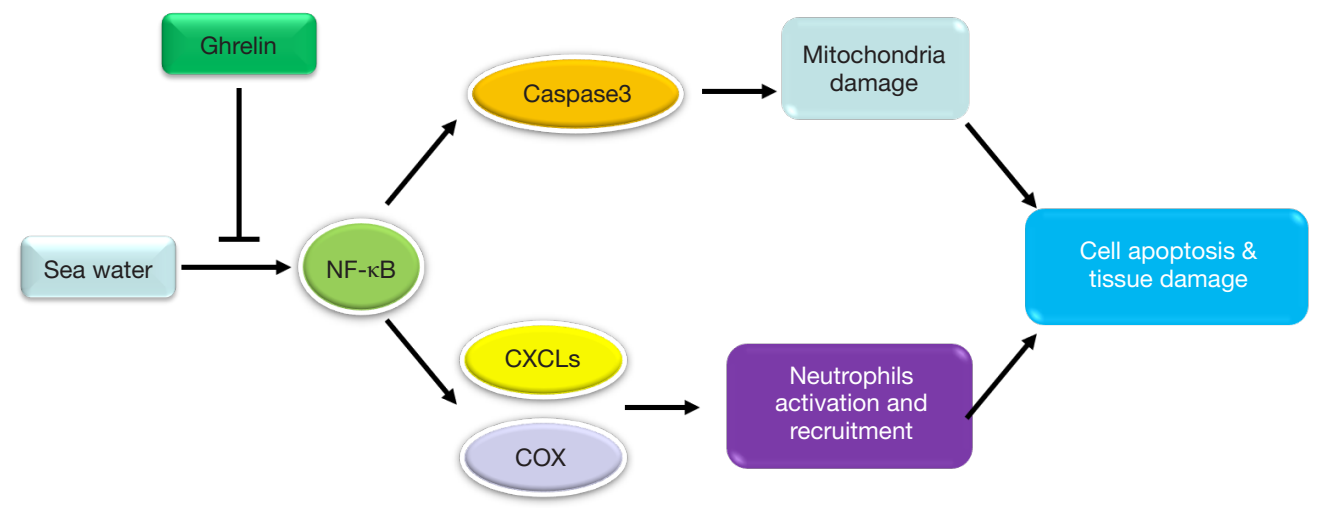

Figure 7 The schematic diagram of ghrelin-mediated protective function on seawater drowning induced lung damage via repressing NF- $\kappa \mathrm{B}$ signaling.

\section{Conclusions}

In this study, we confirmed for the first time that ghrelin can effectively rescue the apoptosis of lung epithelial cells caused by seawater simulants. In vivo experiments also supported that seawater drowning can cause severe pulmonary edema and destruction of the alveolar structure. Further molecular biological determination showed that ghrelin could reduce the activation of NF- $\kappa \mathrm{B}$ signal pathway and phosphorylation of ERK induced by seawater simulants with a concentration dependent effect of ghrelin. Furthermore, ghrelin inhibited the expression of apoptosis related genes and the secretion of inflammatory cytokines. Finally, ghrelin retrieved mitochondrial injury and gradually restored the normal function, including ATP synthesis restart, energy metabolism remodeling, calcium ion and ceramide concentration stable. Interestingly, with the addition of NF- $\kappa \mathrm{B}$ signaling agonists, all the above biological effects mediated by ghrelin, including the reduction of inflammatory signals and the protection of apoptosis, will be restored or partially offset. Therefore, we conclude that seawater drowning can activate NF$\kappa \mathrm{B}$ pathway and induce apoptosis of lung epithelial cells, which are alleviated by ghrelin via inhibiting the activation of NF- $\kappa \mathrm{B}$ pathway.

In addition to direct injury, the activation of various immune cells in the lung tissue is also one of the main reasons for damage induced by seawater drowning. A lot of evidence has shown that alveolar macrophages, pulmonary interstitial macrophages, dendritic cells and neutrophils are involved in a variety of lung injuries repair processes, such as pulmonary fibrosis, acute and chronic pneumonia and infectious lung disease (58). Neutrophils, in particular, can be rapidly activated and recruited to the injured locus at the early stage of inflammation. They can kill pathogenic microorganisms and promote the inflammatory response by producing and releasing a large amount of ROS. It was also reported that the recruitment of neutrophils could further induce the recruitment and activation of macrophages and promote the development of naive $\mathrm{T}$ cells (59). Therefore, blocking the differentiation, maturation, development and recruitment of neutrophils is the key node to control the early outbreak of inflammation. In our study, both in vitro and in vivo results showed that a large number of neutrophils were activated and infiltrated into damaged lung tissue after seawater drowning. Further mechanism studies showed that the damaged lung epithelial cells could promote the generation of inflammatory mediators COX2 and PGE2 and the secretion of chemokines CXCL1 and CXCL2 via activating NF- $\mathrm{BB}$ pathway. The former factors promote the activation of neutrophils, while the latter chemokines are the main chemokines mediating neutrophils recruitment. After administration with ghrelin, the expression and secretion of COX2, PGE2, CXCL1 and CXCL2 were obviously decreased, and the number of neutrophils recruited in the injured lung tissue was also significantly diminished, which is dependent on the inhibition of $\mathrm{NF}-\kappa \mathrm{B}$ signaling pathway by ghrelin. Taken together, our study revealed the protective effect and molecular mechanism of ghrelin on lung injury induced by seawater drowning from the dual perspectives of lung epithelial cell injury and immune cell development (Figure 7). Our work indicated that ghrelin can be used as an adjunctive medicine for seawater drowning, which provides more alternative strategies for clinical treatment. 


\section{Acknowledgments}

We gratefully appreciate Prof. Alex in Xi'an International Studies University to edit the language of the manuscript. The authors would like to acknowledge Fourth Military Medical University for providing the space and equipment for conducting the experiments. We thank the technical staff at Tangdu Hospital, Fourth Military Medical University.

Funding: This work was supported by grants from National Natural Science Foundation of China (81970076).

\section{Footnote}

Reporting Checklist: The authors have completed the ARRIVE reporting checklist. Available at http://dx.doi. org/10.21037/atm-21-795

Data Sharing Statement: Available at http://dx.doi. org/10.21037/atm-21-795

Conflicts of Interest: All authors have completed the ICMJE uniform disclosure form (available at http://dx.doi. org/10.21037/atm-21-795). The authors have no conflicts of interest to declare.

Ethical Statement: The authors are accountable for all aspects of the work in ensuring that questions related to the accuracy or integrity of any part of the work are appropriately investigated and resolved. The animal experiments were performed under a project license (No.: 113-20200269) granted by the Animal Experiment Administration Committee of the Fourth Military Medical University, in compliance with the National Institutes of Health guidelines for care and use of Laboratory Animals [1986 (UK), amended 2013].

Open Access Statement: This is an Open Access article distributed in accordance with the Creative Commons Attribution-NonCommercial-NoDerivs 4.0 International License (CC BY-NC-ND 4.0), which permits the noncommercial replication and distribution of the article with the strict proviso that no changes or edits are made and the original work is properly cited (including links to both the formal publication through the relevant DOI and the license). See: https://creativecommons.org/licenses/by-nc-nd/4.0/.

\section{References}

1. Jin F, Li C. Seawater-drowning-induced acute lung injury:
From molecular mechanisms to potential treatments. Exp Ther Med 2017;13:2591-8.

2. Szpilman D, Morgan P. Management for the Drowning Patient. Chest 2021;159:1473-83.

3. The Lancet. Drowning: a silent killer. Lancet 2017;389:1859.

4. Gregorakos L, Markou N, Psalida V, et al. Near-drowning: clinical course of lung injury in adults. Lung 2009;187:93-7.

5. Matthay MA, McAuley DF, Ware LB. Clinical trials in acute respiratory distress syndrome: challenges and opportunities. Lancet Respir Med 2017;5:524-34.

6. Brodie D, Slutsky AS, Combes A. Extracorporeal Life Support for Adults With Respiratory Failure and Related Indications: A Review. JAMA 2019;322:557-68.

7. Fan E, Brodie D, Slutsky AS. Acute Respiratory Distress Syndrome: Advances in Diagnosis and Treatment. JAMA 2018;319:698-710.

8. Qiu YB, Wan BB, Liu G, et al. Nrf2 protects against seawater drowning-induced acute lung injury via inhibiting ferroptosis. Respir Res 2020;21:232.

9. Schmidt M, Combes A, Shekar K. ECMO for immunosuppressed patients with acute respiratory distress syndrome: drawing a line in the sand. Intensive Care Med 2019;45:1140-2.

10. Sun XQ, Wu C, Qiu YB, et al. Heme oxygenase-1 attenuates seawater drowning-induced acute lung injury through a reduction in inflammation and oxidative stress. Int Immunopharmacol 2019;74:105634.

11. Halmagyi DF. Lung changes and incidence of respiratory arrest in rats after aspiration of sea and fresh water. J Appl Physiol 1961;16:41-4.

12. Ma L, Li Y, Zhao Y, et al. 3,5,4'-tri-O-acetylresveratrol ameliorates seawater exposure-induced lung injury by upregulating connexin 43 expression in lung. Mediators Inflamm 2013;2013:182132.

13. Ma L, Zhao Y, Li B, et al. 3,5,4'-Tri-O-acetylresveratrol attenuates seawater aspiration-induced lung injury by inhibiting activation of nuclear factor-kappa $B$ and hypoxia-inducible factor-1alpha. Respir Physiol Neurobiol 2013;185:608-14.

14. Zhang Y, Zhang B, Xu DQ, et al. Tanshinone IIA attenuates seawater aspiration-induced lung injury by inhibiting macrophage migration inhibitory factor. Biol Pharm Bull 2011;34:1052-7.

15. Folkesson HG, Kheradmand F, Matthay MA. The effect of salt water on alveolar epithelial barrier function. Am J Respir Crit Care Med 1994;150:1555-63.

16. Liu W, Dong M, Bo L, et al. Epigallocatechin-3-gallate 
ameliorates seawater aspiration-induced acute lung injury via regulating inflammatory cytokines and inhibiting JAK/STAT1 pathway in rats. Mediators Inflamm 2014;2014:612593.

17. Liu Z, Xi R, Zhang Z, et al. 4-hydroxyphenylacetic acid attenuated inflammation and edema via suppressing HIF1alpha in seawater aspiration-induced lung injury in rats. Int J Mol Sci 2014;15:12861-84.

18. Liu QP, Zhou DX, Sun L, et al. Bone marrow mesenchymal stem cells ameliorates seawater-exposureinduced acute lung injury by inhibiting autophagy in lung tissue. Patholog Res Int 2014;2014:104962.

19. Liu Z, Zhang B, Wang XB, et al. Hypertonicity contributes to seawater aspiration-induced lung injury: Role of hypoxia-inducible factor 1alpha. Exp Lung Res 2015;41:301-15.

20. Zhang M, Dong M, Liu W, et al. 1alpha,25dihydroxyvitamin D3 ameliorates seawater aspirationinduced acute lung injury via NF-kappaB and RhoA/Rho kinase pathways. PLoS One 2014;9:e104507.

21. Li JH, Xu M, Xie XY, et al. Tanshinone IIA suppresses lung injury and apoptosis, and modulates protein kinase $\mathrm{B}$ and extracellular signal-regulated protein kinase pathways in rats challenged with seawater exposure. Clin Exp Pharmacol Physiol 2011;38:269-77.

22. Rui M, Duan YY, Zhang XH, et al. Urinary trypsin inhibitor attenuates seawater-induced acute lung injury by influencing the activities of nuclear factor- $\mathrm{kB}$ and its related inflammatory mediators. Respiration 2012;83:335-43.

23. Xinmin D, Yunyou D, Chaosheng P, et al. Dexamethasone treatment attenuates early seawater instillation-induced acute lung injury in rabbits. Pharmacol Res 2006;53:372-9.

24. Zhou CH, Li X, Zhu YZ, et al. Ghrelin alleviates neuropathic pain through GHSR-1a-mediated suppression of the p38 MAPK/NF-kappaB pathway in a rat chronic constriction injury model. Reg Anesth Pain Med 2014;39:137-48.

25. Zhou X, Xue C. Ghrelin inhibits the development of acute pancreatitis and nuclear factor kappaB activation in pancreas and liver. Pancreas 2009;38:752-7.

26. Cheng J, Zhang L, Dai W, et al. Ghrelin ameliorates intestinal barrier dysfunction in experimental colitis by inhibiting the activation of nuclear factor-kappa B. Biochem Biophys Res Commun 2015;458:140-7.

27. Peng Z, Zhu Y, Zhang Y, et al. Effects of ghrelin on pulmonary NOD2 mRNA expression and NF-kappaB activation when protects against acute lung injury in rats challenged with cecal ligation and puncture. Int
Immunopharmacol 2012;13:440-5.

28. Wu R, Dong W, Zhou M, et al. Ghrelin attenuates sepsisinduced acute lung injury and mortality in rats. Am J Respir Crit Care Med 2007;176:805-13.

29. Sen L, Karakoyun B, Yegen C, et al. Treatment with either obestatin or ghrelin attenuates mesenteric ischemiareperfusion-induced oxidative injury of the ileum and the remote organ lung. Peptides 2015;71:8-19.

30. Wu R, Dong W, Ji Y, et al. Orexigenic hormone ghrelin attenuates local and remote organ injury after intestinal ischemia-reperfusion. PLoS One 2008;3:e2026.

31. Chen J, Liu X, Shu Q, et al. Ghrelin attenuates lipopolysaccharide-induced acute lung injury through NO pathway. Med Sci Monit 2008;14:BR141-6.

32. Li G, Li J, Zhou Q, et al. Growth hormone releasing peptide-2, a ghrelin agonist, attenuates lipopolysaccharideinduced acute lung injury in rats. Tohoku J Exp Med 2010;222:7-13.

33. Imazu Y, Yanagi S, Miyoshi K, et al. Ghrelin ameliorates bleomycin-induced acute lung injury by protecting alveolar epithelial cells and suppressing lung inflammation. Eur J Pharmacol 2011;672:153-8.

34. Tsubouchi H, Yanagi S, Miura A, et al. Rikkunshito ameliorates bleomycin-induced acute lung injury in a ghrelin-independent manner. Am J Physiol Lung Cell Mol Physiol 2014;306:L233-45.

35. Sun N, Wang H, Ma L, et al. Ghrelin attenuates brain injury in septic mice via PI3K/Akt signaling activation. Brain Res Bull 2016;124:278-85.

36. Wang W, Bansal S, Falk S, et al. Ghrelin protects mice against endotoxemia-induced acute kidney injury. Am J Physiol Renal Physiol 2009;297:F1032-7.

37. Qi L, Cui XX, Dong WF, et al. Ghrelin Protects Rats Against Traumatic Brain Injury and Hemorrhagic Shock Through Upregulation of UCP2. Annals of Surgery 2014;260:169-78.

38. Wu R, Dong W, Cui X, et al. Ghrelin down-regulates proinflammatory cytokines in sepsis through activation of the vagus nerve. Ann Surg 2007;245:480-6.

39. Cao Y, Tang J, Yang T, et al. Cardioprotective Effect of Ghrelin in Cardiopulmonary Bypass Involves a Reduction in Inflammatory Response. PLoS One 2013;8:e55021.

40. Mani BK, Zigman JM. Ghrelin as a Survival Hormone. Trends Endocrinol Metab 2017;28:843-54.

41. Xiao X, Bi M, Jiao Q, et al. A new understanding of GHSR1a--independent of ghrelin activation. Ageing Res Rev 2020;64:101187.

42. Yanagi S, Sato T, Kangawa K, et al. The Homeostatic 
Force of Ghrelin. Cell Metab 2018;27:786-804.

43. Capece D, Verzella D, Di Francesco B, et al. NF-kappaB and mitochondria cross paths in cancer: mitochondrial metabolism and beyond. Semin Cell Dev Biol 2020;98:118-28.

44. Yu H, Lin L, Zhang Z, et al. Targeting NF-kappaB pathway for the therapy of diseases: mechanism and clinical study. Signal Transduct Target Ther 2020;5:209.

45. Robert A, Danin PE, Quintard H, et al. Seawater drowning-associated pneumonia: a 10-year descriptive cohort in intensive care unit. Ann Intensive Care 2017;7:45.

46. Foex BA, Boyd R. Towards evidence based emergency medicine: best BETs from the Manchester Royal Infirmary. Corticosteroids in the management of near-drowning. Emerg Med J 2001;18:465-6.

47. Munt PW, Fleetham JA. Corticosteroids and neardrowning. Lancet 1978;1:665-6.

48. Buntwal L, Sassi M, Morgan AH, et al. Ghrelin-Mediated Hippocampal Neurogenesis: Implications for Health and Disease. Trends Endocrinol Metab 2019;30:844-59.

49. Stone LA, Harmatz ES, Goosens KA. Ghrelin as a Stress Hormone: Implications for Psychiatric Illness. Biol Psychiatry 2020;88:531-40.

50. Al-Massadi O, Muller T, Tschop M, et al. Ghrelin and LEAP-2: Rivals in Energy Metabolism. Trends Pharmacol Sci 2018;39:685-94.

51. Chen CY, Asakawa A, Fujimiya M, et al. Ghrelin gene products and the regulation of food intake and gut motility. Pharmacol Rev 2009;61:430-81.

Cite this article as: Chen M, Lin H, Gao Y, Wang Z, Li Y, Jin F. Ghrelin attenuates drowning injury via dual effects on damage protection and immune repression. Ann Transl Med 2021;9(11):920. doi: 10.21037/atm-21-795
52. Gortan Cappellari G, Zanetti M, Semolic A, et al. Unacylated Ghrelin Reduces Skeletal Muscle Reactive Oxygen Species Generation and Inflammation and Prevents High-Fat Diet-Induced Hyperglycemia and Whole-Body Insulin Resistance in Rodents. Diabetes 2016;65:874-86.

53. Harisseh R, Pillot B, Gharib A, et al. Unacylated ghrelin analog prevents myocardial reperfusion injury independently of permeability transition pore. Basic Res Cardiol 2017;112:4.

54. Nikitopoulou I, Kampisiouli E, Jahaj E, et al. Ghrelin alterations during experimental and human sepsis. Cytokine 2020;127:154937.

55. Ercan S, Basaranlar G, Gungor NE, et al. Ghrelin inhibits sodium metabisulfite induced oxidative stress and apoptosis in rat gastric mucosa. Food Chem Toxicol 2013;56:154-61.

56. Francisco V, Tovar S, Conde J, et al. Levels of the Novel Endogenous Antagonist of Ghrelin Receptor, LiverEnriched Antimicrobial Peptide-2, in Patients with Rheumatoid Arthritis. Nutrients 2020;12:1006.

57. Liu J, Cao L, Gao X, et al. Ghrelin prevents articular cartilage matrix destruction in human chondrocytes. Biomed Pharmacother 2018;98:651-5.

58. Hiemstra PS, McCray PB Jr, Bals R. The innate immune function of airway epithelial cells in inflammatory lung disease. Eur Respir J 2015;45:1150-62.

59. Adrover JM, Del Fresno C, Crainiciuc G, et al. A Neutrophil Timer Coordinates Immune Defense and Vascular Protection. Immunity 2019;50:390-402.e10. 